\title{
Facial nerve outcomes after surgery for large vestibular schwannomas: do surgical approach and extent of resection matter?
}

\author{
Richard K. Gurgel, M.D., ${ }^{1}$ Salim Dogru, M.D., ${ }^{2}$ Richard L. Amdur, Ph.D., ${ }^{3}$ \\ and Ashikan Monfared, M.D. ${ }^{3,4}$ \\ ${ }^{1}$ Department of Otolaryngology, Stanford University, Stanford, California; ${ }^{2}$ Department of Otolaryngology, \\ GATA-Haydarpasa Military Hospital, Istanbul, Turkey; and Departments of ${ }^{3}$ Surgery and ${ }^{4}$ Neurosurgery, \\ George Washington University, Washington, DC
}

\begin{abstract}
Object. The object of this study was to evaluate facial nerve outcomes in the surgical treatment of large vestibular schwannomas (VSs; $\geq 2.5 \mathrm{~cm}$ maximal or extrameatal cerebellopontine angle diameter) based on both the operative approach and extent of tumor resection.

Methods. A PubMed search was conducted of English language studies on the treatment of large VSs published from 1985 to 2011. Studies were then evaluated and included if they contained data regarding the size of the tumor, surgical approach, extent of resection, and postoperative facial nerve function.

Results. Of the 536 studies initially screened, 59 full-text articles were assessed for eligibility, and 30 studies were included for analysis. A total of 1688 tumor resections were reported. Surgical approach was reported in 1390 patients and was significantly associated with facial nerve outcome $(\phi=0.29, \mathrm{p}<0.0001)$. Good facial nerve outcomes (House-Brackmann Grade I or II) were produced in $62.5 \%$ of the 555 translabyrinthine approaches, $65.2 \%$ of the 601 retrosigmoid approaches, and $27.4 \%$ of the 234 extended translabyrinthine approaches. Facial nerve outcomes from translabyrinthine and retrosigmoid approaches were not significantly different from each other, but both showed significantly more good facial nerve outcomes, compared with the extended translabyrinthine approach (OR for translabyrinthine vs extended translabyrinthine $=4.43,95 \%$ CI 3.17-6.19, $\mathrm{p}<0.0001$; OR for retrosigmoid vs extended translabyrinthine $=4.98,95 \%$ CI $3.57-6.95, \mathrm{p}<0.0001$ ). There were 471 patients for whom extent of resection was reported. There was a strong and significant association between degree of resection and outcome $(\phi=$ $0.38, \mathrm{p}<0.0001)$. Of the 80 patients receiving subtotal resections, $92.5 \%$ had good facial nerve outcomes, compared with $74.6 \%(n=55)$ and $47.3 \%(n=336)$ of those who received near-total resections and gross-total resections, respectively. In the 2-way comparison of good versus suboptimal/poor outcomes (House-Brackmann Grade III-VI), subtotal resection was significantly better than near-total resection $(\mathrm{OR}=4.21,95 \% \mathrm{CI} 1.50-11.79 ; \mathrm{p}=0.004)$, and near-total resection was significantly better than gross-total resection $(\mathrm{OR}=3.26,95 \% \mathrm{CI} 1.71-6.20 ; \mathrm{p}=0.0002)$ in producing better facial nerve outcomes.

Conclusions. In a pooled patient population from studies evaluating the treatment of large VSs, subtotal and near-total resections were shown to produce better facial nerve outcomes when compared with gross-total resections. The translabyrinthine and retrosigmoid surgical approaches are likely to result in similar rates of good facial nerve outcomes. Both of these approaches show better facial nerve outcomes when compared with the extended translabyrinthine approach, which is typically reserved for especially large tumors. The reported literature on treatment of large VSs is extremely heterogeneous and minimal consistency in reporting outcomes was observed. (http://thejns.org/doi/abs/10.3171/2012.7.FOCUS12199)
\end{abstract}

\section{KeY Words • vestibular schwannoma — facial nerve outcome • subtotal resection $\quad$ - translabyrinthine approach $\quad$ retrosigmoid approach $\bullet$ near-total resection}

I $\mathrm{N}$ the era of modern microsurgery, surgical outcomes for the removal of VSs have markedly improved. ${ }^{14,24,35}$ Despite advancements in facial nerve monitoring and surgical techniques, functional preservation of the facial nerve in surgery for larger tumors remains a challenge. ${ }^{4,36}$ For small and medium-sized tumors, long-term

\footnotetext{
Abbreviations used in this paper: GTR = gross-total resection; $\mathrm{NTR}=$ near-total resection; STR = subtotal resection; VS = vestibular schwannoma.
}

facial nerve preservation rates are reported to be more than $90 \%$, but this rate is substantially lower for large tumors. ${ }^{20,29}$

Series of large VSs frequently have been published as distinct clinical entities, because large tumors present a greater challenge to surgeons regarding total removal, cranial nerve preservation, and other postoperative complications..$^{32,49}$ Due to the paucity of data for such large tumors, a systematic literature review of all the available reports would be greatly beneficial in determining opti- 
mal treatment strategies. What renders this task nearly insurmountable is the lack of reporting standardization for VS outcomes. In these series, except for the HouseBrackmann grading system of facial nerve function, there appears to be no agreement on what is the minimum size of a "large" tumor, measurement of tumor size, and degree of resection. ${ }^{23}$ Instead of enumerating the inconsistencies in the reported literature, we will define each variable we measured in the Methods section and then indicate specific issues with each included paper in the Results and Discussion sections.

The ideal therapeutic goal in VS surgery is complete removal of the tumor in a single stage with complete preservation of all cranial nerve function. However, for larger tumors, this has remained an elusive goal. For this reason, many studies have advocated partial resections, 2-stage resections, and combined partial resection with radiation therapy. 3,17,40,42 Moreover, questions remain regarding the surgical approach that provides the optimal facial nerve outcome.

In this study, we systematically reviewed studies reporting postoperative outcomes of large VSs $(\geq 2.5 \mathrm{~cm}$ of maximal or extrameatal diameter), with special attention to the facial nerve outcomes as a function of surgical approach and degree of tumor resection.

\section{Methods}

\section{Search Criteria}

Following an Institutional Review Board exemption, we conducted a systematic review using a PubMed search of the English language literature from 1985 to 2011. The date range was chosen to represent the era of more routine use of facial nerve monitoring in VS surgery. The search terms "large acoustic neuroma," "large vestibular schwannoma," "acoustic neuroma surgical resection," "acoustic neuromas retrosigmoid," "acoustic neuromas translabyrinthine," "subtotal resection acoustic neuroma," "vestibular schwannoma," and "acoustic neuroma" were used to identify appropriate papers. Figure 1 provides a flowchart of the number of papers identified, screened, and included in the study. The 59 full-text articles assessed for eligibility were all screened independently by 3 of the authors (R.K.G., S.D., and A.M.).

Studies were screened for data on large VSs defined by a greatest extrameatal diameter of at least $2.5 \mathrm{~cm}$ according to the Kanzaki standard, largest diameter, or a Koos classification $\geq 4 .{ }^{28}$ We did not exclude papers if they did not measure extrameatal diameter only. The majority of included papers $(22 / 30,73 \%)$ reported extrameatal measurement, while $17 \%$ reported sizes at least 2.5 $\mathrm{cm}$ in largest dimension (in all but 1 of these studies, the smallest tumor was $3.0 \mathrm{~cm}$ in longest dimension), $7 \%$ of papers used the Koos classification, and 1 paper did not state how measurements were obtained, although tumors in this paper were still reported as $>2.5 \mathrm{~cm}$.

Studies were included if facial nerve data along with surgical approach and/or extent of resection were provided. Extent of resection as GTR, NTR, or STR was determined as defined by each author. Facial nerve outcomes were determined by the House-Brackmann grading scale. ${ }^{23}$ Any anatomically disrupted facial nerves were given a VI/VI grade, even if a subsequent hypoglossalfacial or primary anastomosis of the nerve provided improved facial nerve outcome. Papers that reported surgery without continuous intraoperative facial nerve monitoring were excluded. If papers clearly identified neurofibromatosis Type 2 patients and their outcomes, those patients were excluded from analysis because of the more aggressive nature and neural invasiveness of the disease. ${ }^{39}$

\section{Assessment of Study Quality}

After inclusion, each paper was given a relative value score by assigning points for quality of the paper. The grading system included 1 or 0 points for the respective presence or absence of the following: average tumor size reported, inclusion of neurofibromatosis Type 2 patients reported, tumor measurement of largest extrameatal diameter specifically mentioned, facial nerve function reported as function of approach, facial nerve function reported as function of degree of resection, degree of resection, postoperative MRI correlation of extent of resection reported, and postoperative follow-up of at least 12 months. Degree of cranial nerve function was used to measure treatment outcome. Outcome levels of good (House-Brackmann Grade I or II), suboptimal (HouseBrackmann Grade III or IV), and poor (House-Brackmann Grade V or VI) were compared.

\section{Surgical Approach and Extent of Resection}

Treatment outcomes for the 3 surgical approaches (translabyrinthine, retrosigmoid, and extended translabyrinthine) and 3 degrees of resection (STR, NTR, and GTR) were compared across all studies by summing the number of patients with good, suboptimal, and poor facial nerve outcomes, and using a $3 \times 3$ chi-square to evaluate the association of treatment outcome with surgical approach and degree of resection. If these analyses were significant, each pair of treatments was compared in a 2 $\times 2$ chi-square examining good versus suboptimal/poor facial nerve outcomes.

The extended translabyrinthine approach is defined as any standard translabyrinthine approach that was modified to provide greater access for extremely large tumors. These modifications included the translabyrinthine-transapical exposure described by Angeli et al. ${ }^{2}$ in which the IAC is opened with greater than $300^{\circ}$ of exposure, or the combined translabyrinthine-retrosigmoid exposure as described by Anderson et al. ${ }^{1}$

The definition of what constitutes an NTR compared with an STR varies by author, with no universally agreedupon definition. Some authors have subjectively defined the residual tumor with words such as "minimal," "tiny," "small" amount, or "thin layer" of residual tumor, as defined by the operative surgeon. ${ }^{33,43,47}$ Bloch et al. ${ }^{3}$ defined an NTR as $25 \mathrm{~mm}^{2}$ or a 2-mm-thick pad of residual tumor, and an STR as anything less than an NTR. Haque et al. ${ }^{22}$ defined an STR as when $>90 \%$ of the tumor was removed and GTR as when the entire tumor was microscopically removed. For studies that reported extent of resection, the 
Facial nerve outcomes in surgery for large vestibular schwannomas

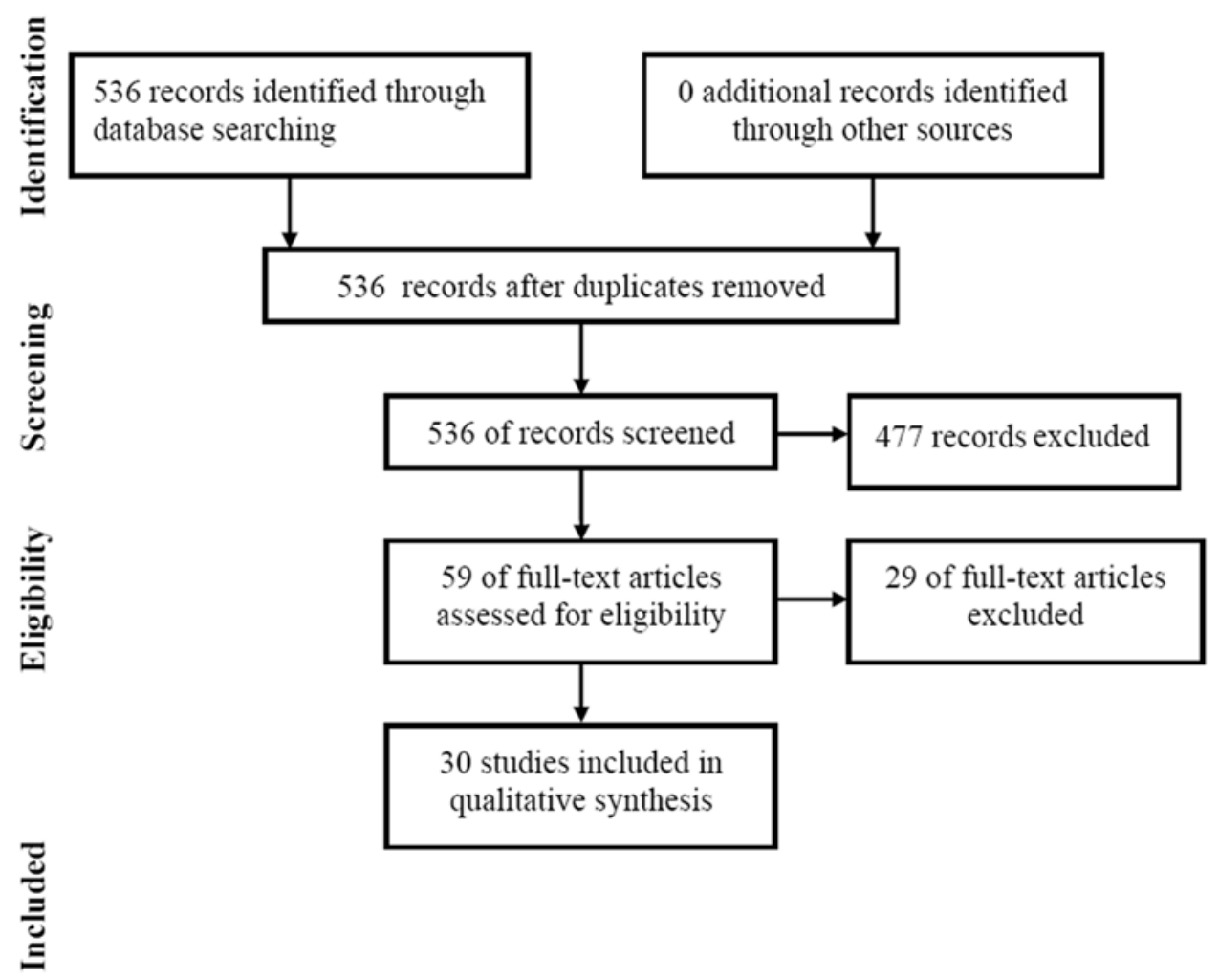

Fig. 1. This flowchart illustrates how many articles were initially identified, screened, and included in the study analysis.

most commonly used definition in this systematic review was that an STR represented $>5 \%$ of residual tumor, and an NTR was any residual tumor $\leq 5 \% .^{2,21,31,57}$

\section{Statistical Analysis}

The percentage of surgeries with good facial nerve outcome (House-Brackmann Grade I or II) was examined across studies. Univariate Pearson correlations were examined across studies, between percentage of functional outcomes, and other study characteristics including date of publication, number of tumors, size cutoff used to define large tumors, and average patient age. Multiple regression analysis was used to test multivariate models predicting functional outcomes, to try to determine whether degree of resection or type of approach had an independent association with outcome, after controlling for other study characteristics.

Statistics were calculated using SAS version 9.2 (SAS Institute, Inc.) and graphs were created using Microsoft Excel.

\section{Results}

Of the 536 papers initially identified, 30 fit our criteria, all of which were retrospective case series. ${ }^{1,2,4,7,8,12}$, $13,18,21,25,27,30-34,37,38,41,43-46,48,50-52,54,55,57$ Table 1 summarizes the characteristics of each paper. The retrospective nature of the papers and heterogeneity in reporting tumor size, degree of tumor resection, indications for degree of resection, length of follow-up, and reporting facial nerve outcome for individual groups (degree of resection and surgical approach) precluded a true statistical meta-analysis.

\section{Tumor Size}

One thousand six hundred and eighty-eight tumors measuring at least $2.5 \mathrm{~cm}$ were reported. The average size of the tumor was $3.9 \mathrm{~cm}$ in the $40 \%$ of papers that reported an average size. In regard to measuring the dimensions of the tumor, 21 studies reported the longest measurement in the cerebellopontine angle excluding the portion of the tumor in the internal auditory canal, 6 reported the absolute longest dimension, 2 used the Koos classification, and 1 made no mention of measurement criteria.

\section{Surgical Approach}

Of the 1636 cases for which a surgical approach was mentioned, 729 underwent translabyrinthine, 644 retrosigmoid, and 263 extended translabyrinthine tumor resection. Ten papers provided a definition for what consisted of less-than-total resection of tumor, and only 4 of those used the Kanzaki standards. ${ }^{28,45}$ Two studies contained only patients who underwent less-than-total resection.

\section{Extent of Resection}

We were able to decipher the approximate degree of resection for 1158 patients, of whom 938 underwent GTR, 102 NTR, and 147 STR. Only 2 papers correlated their surgical degree of resection with postoperative MR images. Twenty-one papers reported facial nerve outcome after 12 months of follow-up. Fourteen papers reported facial nerve outcome as a function of degree of resection, and 471 patients' treatments were examined. Of these pa- 
R. K. Gurgel et al.

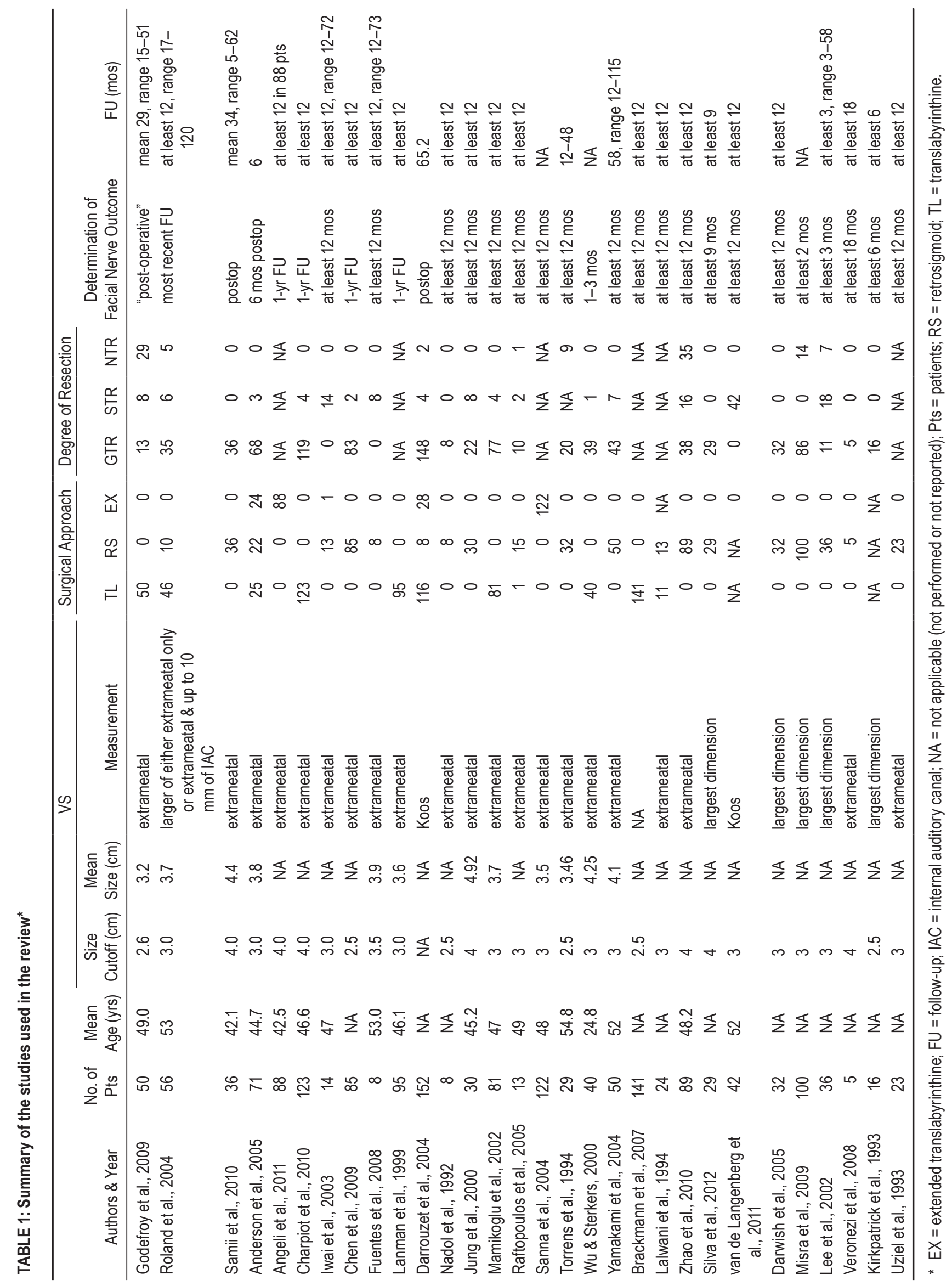


tients, 274 (58\%) had good facial nerve outcomes (HouseBrackmann Grade I or II), 104 (22\%) were suboptimal (House-Brackmann Grade III or IV), and 93 (20\%) were poor (House-Brackmann Grade V or VI). There was a strong and significant association between degree of resection and outcome $(\phi=0.38, \mathrm{p}<0.0001)$. Of the 80 patients receiving STR, $92.5 \%$ had good facial nerve outcomes, compared with $74.6 \%(n=55)$ and $47.3 \%(n=$ 336) of those who received NTR and GTR, respectively (Fig. 2). In the 2-way comparison of good versus suboptimal/poor outcomes (House-Brackmann Grade III-VI), STR was significantly better than NTR $(\mathrm{OR}=4.21,95 \%$ CI 1.50-11.79; $\mathrm{p}=0.004)$, and NTR was significantly better than GTR $(\mathrm{OR}=3.26,95 \%$ CI $1.71-6.20 ; p=0.0002)$ in producing better facial nerve outcomes. A Forrest plot was created to display the effect sizes for facial nerve outcomes for all studies reporting on degree of resection (Fig. 3).

\section{Facial Nerve Outcome}

We were able to identify the facial nerve outcome as the function of surgical approach in 27 of the papers. Studies reported outcomes for 1390 patients, 803 (58\%) with good facial nerve outcomes, 365 suboptimal (26\%), and $222(16 \%)$ with poor outcomes. Surgical approach was significantly associated with outcome $(\phi=0.29, \mathrm{p}<$ $0.0001)$. Good facial nerve outcomes were produced in $62.5 \%$ of the 555 translabyrinthine approaches, $65.2 \%$ of the 601 treatments using the retrosigmoid approach, and $27.4 \%$ of the 234 treatments using the extended translabyrinthine approach (Fig. 4). Facial nerve outcomes from translabyrinthine and retrosigmoid approaches were not significantly different from each other, but both produced significantly more good outcomes compared with the extended translabyrinthine approach (OR for translabyrinthine vs extended translabyrinthine approach $=4.43,95 \%$ CI 3.17-6.19, p < 0.0001; OR for retrosigmoid vs extended translabyrinthine approach $=4.98,95 \%$ CI 3.57-6.95, $\mathrm{p}<0.0001)$.

The mean percentage of surgeries with good facial nerve outcomes was $0.61 \pm 0.24$ (95\% CI 0.52-0.70). In univariate analysis, patient age, year published, and number of tumors were not significantly related to percentage of functional outcomes, but size cutoff used to define large

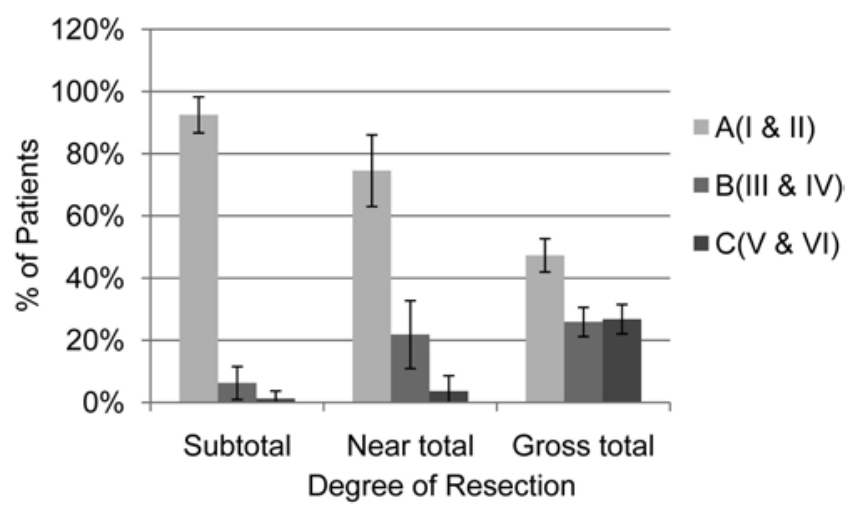

FıG. 2. Graph of facial nerve outcome (3 levels, $A-C$ ) according to degree of resection. Error bars $=95 \% \mathrm{Cls}$. I-VI $=$ House-Brackmann grades.

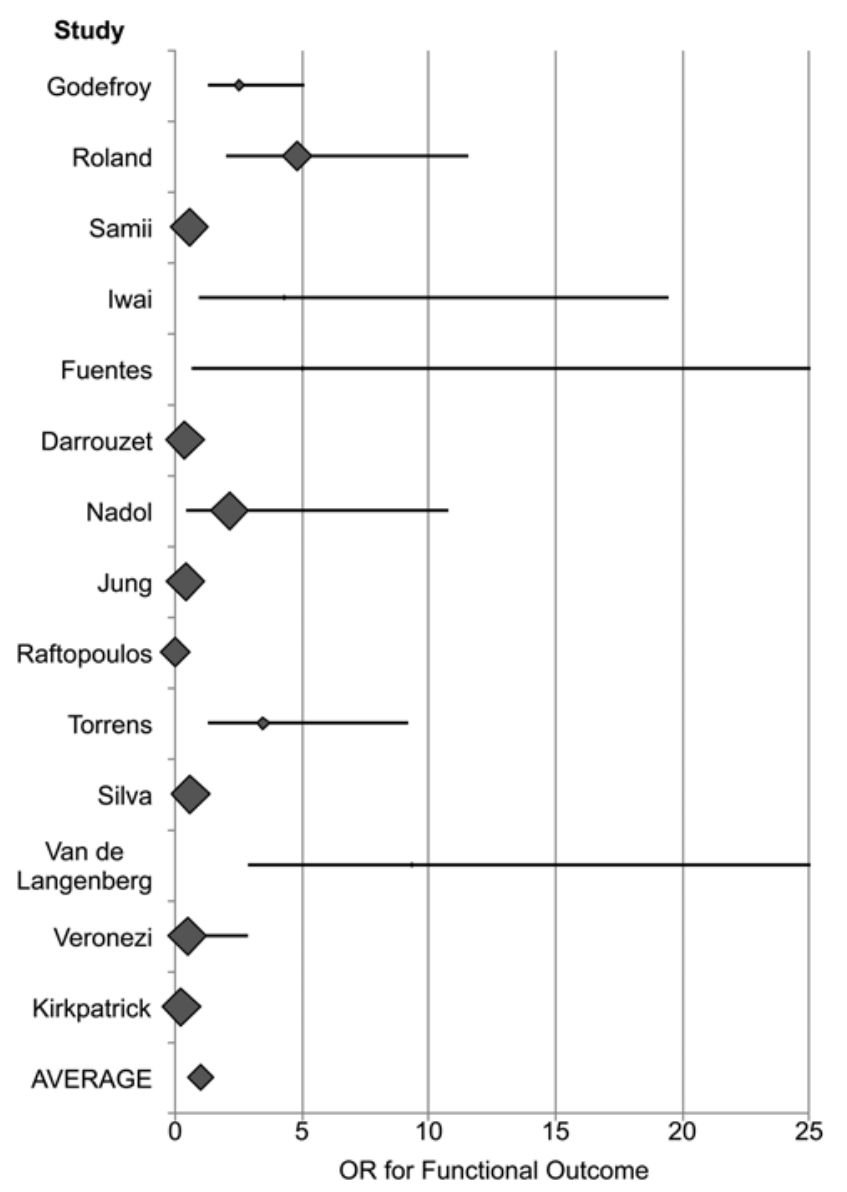

FIG. 3. Forrest plot of effect sizes (OR) for good facial nerve outcomes (House-Brackmann Grade I or II) for all studies reporting on degree of resection. Horizontal lines $=95 \%$ Cls. Vertical dashed line = average effect size. Size of diamond is proportional to the percentage of resections that were GTR (larger diamond indicates more GTRs, smaller diamond indicates more NTRs or STRs).

tumors was significantly associated $(\mathrm{r}=-0.43, \mathrm{p}<0.02)$. This indicated that studies with larger size cutoffs tended to have fewer patients with good facial nerve outcomes. Multiple regression models were tested with predictors including size cutoff, number of treatments using translabyrinthine, retrosigmoid, or extended translabyrinthine approaches, and number using GTR, NTR, and STR. We found a model that was significant $(\mathrm{p}<0.001)$ with moderate prediction accuracy $\left(\mathrm{R}^{2}=0.48\right)$, which included the predictors size cutoff, number of subtotal resections, and number of surgeries using the extended translabyrinthine approach. In this model, after accounting for other variables in the model, size cutoff and extended translabyrinthine approach were negatively associated with functional outcomes ( $p=0.02$ and 0.03 , respectively), while STR was positively associated with functional outcomes $(\mathrm{p}=0.01)$. Thus, each of these 3 variables independently predicted the percentage of good facial nerve outcomes across studies.

\section{Discussion}

The goal in managing VSs is to control tumor growth 


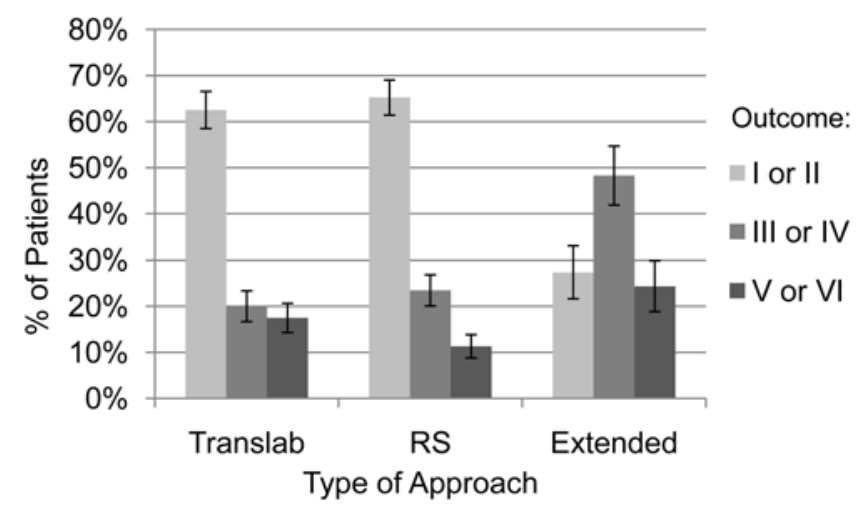

FIG. 4. Graph of facial nerve outcome (3 levels) according to surgical approach. $\mathrm{RS}=$ retrosigmoid; Translab = translabyrinthine.

while preserving neurological function. Large VSs pose a particular challenge in attaining this goal. Many reports have cited the high rate of poor facial nerve outcomes following microsurgical resection of VSs. ${ }^{5,27,32,34,44,53,56}$ In these studies, facial nerve outcomes of House-Brackmann Grade I or II were reported in only $27 \%-58 \%$ of patients with VSs $\geq 3.0 \mathrm{~cm}$ following GTR. Facial nerve preservation is particularly difficult in large tumors because as the tumor slowly enlarges, the facial nerve becomes stretched and often "ribbons" over the surface of the tumor. ${ }^{3}$ Moreover, the tumor-arachnoid dissection plane is often obscured as the tumor enlarges. ${ }^{9}$ This is particularly true just medial to the porous acusticus, where a pressure "bottleneck" can occur at the entrance of the bony internal auditory canal.

\section{Surgical Approach}

The findings of this study suggest that there is no statistically significant difference in facial nerve outcomes between the translabyrinthine and retrosigmoid approaches. However, there was a difference between the extended translabyrinthine and either the translabyrinthine or retrosigmoid approach. As described by Sanna et al., ${ }^{45}$ the extended translabyrinthine approach is a modification of the translabyrinthine approach, which allows for greater exposure for especially large VSs. The finding that the extended translabyrinthine approach resulted in poor facial nerve outcomes is likely due to a selection bias of patients with particularly large VSs, and possibly recurrent tumors operated on at that institution, thus warranting the extended approach.

\section{Extent of Resection}

The goal of microsurgical VS resection has traditionally been microscropic GTR. In the era of high-quality imaging modalities and treatment modalities, such as stereotactic radiation with excellent tumor control rates, is total resection warranted for a benign tumor when the facial nerve would be put at high risk for postoperative dysfunction? Answering this question has led to the concept of partial resections of VSs if GTR cannot be achieved without injuring the facial nerve.

The controversy over partial resection dates back to the 2 surgeons who truly revolutionized the art of acoustic neuroma resection, Harvey Cushing and Walter Dandy. Cushing advocated a partial resection, which was vehemently opposed by Dandy, considering the high mortality rate of recurrent tumors. ${ }^{10,11,15}$ William House reported in $1968^{24}$ that partial removal was a reasonable alternative to total removal when intraoperative vital signs were labile, or for "the elderly patient, or the patient who is poor surgical risk."

The results of this study show that STR of large VSs results in improved facial nerve outcomes when compared with NTR and GTR. Facial nerve outcomes of NTR are also improved when compared with results of GTR. This result is not surprising given that partial resections likely cause less surgical trauma to the nerve compared with GTRs.

We were unable to evaluate rates of recurrence in the present study due to lack of data. Only 4 papers made any comments on recurrence and most did not have sufficiently long follow-up. However, in general VS literature, there are considerable data to suggest that the rate of recurrence is correlated with the amount of residual tumor following resection. El-Kashlan et al. ${ }^{16}$ reported that $43.6 \%$ of their 39 patients showed signs of VS regrowth following STR and NTR after a mean follow-up period of 6.2 years (range 3.5-10.2 years). No patient in their series, however, experienced regrowth following tumor resection greater than $98 \%(n=8)$. Residual postoperative tumor thickness of $10.9 \pm 4.1 \mathrm{~mm}$ versus $5.7 \pm 3.0 \mathrm{~mm}$ has been shown to be a risk factor for regrowth $(\mathrm{p}<0.001) .{ }^{19}$ Carlson et al. ${ }^{6}$ reported that in 350 patients with VSs treated with microsurgical resection, patients receiving STR were more than 9 times more likely to experience recurrence compared with those undergoing NTR or GTR $(\mathrm{p}<0.001)$. Whereas GTR is optimal to prevent tumor recurrence, NTR appears to provide similarly low recurrence rates, likely due to a lack of adequate blood supply or critical tumor mass following NTR to allow subsequent growth. ${ }^{3}$

The major limitations of this study include the retrospective and often uncontrolled nature of the studies included. Many surgeons with high volumes of patients only used 1 approach, which makes clear comparison between surgical approaches difficult. Also, certain centers would only perform GTR or STR. The decision as to degree of tumor resection largely depends on the surgeon and intraoperative findings, which is an inherent bias of the literature: the more difficult, aggressive, and adherent tumors probably were resected in a less-than-total fashion. Studies also often included heterogeneous populations; some reported on patients with preoperative facial palsy or included patients with neurofibromatosis Type 2 and those with unilateral, sporadic VS in the same patient population. Neurofibromatosis Type 2 tumors are more infiltrative of the facial nerve than unilateral, sporadic VSs, and will therefore be more likely to cause facial palsy following GTR. ${ }^{39}$

The results of this current review should be viewed considering the limitations of the available literature. As this study sought to pool similar data from many studies, it was imperative that the patients be similar. Despite our best efforts to compare similar populations, there were limitations due to variability in reporting tumor size, 


\section{Facial nerve outcomes in surgery for large vestibular schwannomas}

facial nerve outcome, degree of resection, and length of follow-up. In 2003, Kanzaki et al. ${ }^{28}$ reported on minimal standards for describing outcomes in VS surgery. Unfortunately, these standards have yet to be universally implemented, but would aid in comparing data for studies such as this. ${ }^{26}$ We recommend creating more strict reporting guidelines for surgeons interested in publishing their series of VS resections, similar to the House-Brackmann facial nerve outcome. Also, a prospective, multicenter study would limit some of the biases affecting the literature and is currently underway (http://clinicaltrials.gov/ ct2/show/NCT01129687).

\section{Conclusions}

The surgical treatment of large VSs often leads to suboptimal and poor facial nerve outcomes. Taking into account the inherent biases in the literature, STR and NTR appear to produce improved facial nerve outcomes when compared with GTR. The retrosigmoid and translabyrinthine surgical approaches both provide similar rates of facial nerve outcomes. Both of these approaches have better facial nerve outcomes when compared with the extended translabyrinthine approach, which is typically reserved for especially large tumors. The reported literature on treatment of large VSs is extremely heterogeneous, and minimal consistency in reporting outcomes was observed.

\section{Disclosure}

The authors report no conflict of interest concerning the materials or methods used in this study or the findings specified in this paper.

Author contributions to the study and manuscript preparation include the following. Conception and design: Monfared, Gurgel. Acquisition of data: Monfared, Gurgel, Dogru. Analysis and interpretation of data: Monfared, Gurgel, Dogru. Drafting the article: Monfared, Gurgel, Dogru. Critically revising the article: all authors. Reviewed submitted version of manuscript: all authors. Approved the final version of the manuscript on behalf of all authors: Monfared. Statistical analysis: Amdur. Administrative/technical/material support: Monfared, Gurgel, Dogru. Study supervision: Monfared.

\section{References}

1. Anderson DE, Leonetti J, Wind JJ, Cribari D, Fahey K: Resection of large vestibular schwannomas: facial nerve preservation in the context of surgical approach and patient-assessed outcome. J Neurosurg 102:643-649, 2005

2. Angeli RD, Piccirillo E, Di Trapani G, Sequino G, Taibah A, Sanna M: Enlarged translabyrinthine approach with transapical extension in the management of giant vestibular schwannomas: personal experience and review of literature. Otol Neurotol 32:125-131, 2011

3. Bloch DC, Oghalai JS, Jackler RK, Osofsky M, Pitts LH: The fate of the tumor remnant after less-than-complete acoustic neuroma resection. Otolaryngol Head Neck Surg 130:104112,2004

4. Brackmann DE, Cullen RD, Fisher LM: Facial nerve function after translabyrinthine vestibular schwannoma surgery. Otolaryngol Head Neck Surg 136:773-777, 2007

5. Briggs RJ, Luxford WM, Atkins JS Jr, Hitselberger WE: Translabyrinthine removal of large acoustic neuromas. Neurosurgery 34:785-791, 1994

6. Carlson ML, Van Abel KM, Driscoll CL, Neff BA, Beatty
CW, Lane JI, et al: Magnetic resonance imaging surveillance following vestibular schwannoma resection. Laryngoscope 122:378-388, 2012

7. Charpiot A, Tringali S, Zaouche S, Ferber-Viart C, Dubreuil $\mathrm{C}$ : Perioperative complications after translabyrinthine removal of large or giant vestibular schwannoma: outcomes for 123 patients. Acta Otolaryngol 130:1249-1255, 2010

8. Chen L, Chen L, Liu L, Ling F, Yuan X, Fang J, et al: Vestibular schwannoma microsurgery with special reference to facial nerve preservation. Clin Neurol Neurosurg 111:47-53, 2009

9. Comey CH, Jannetta PJ, Sheptak PE, Joh HD, Burkhart LE: Staged removal of acoustic tumors: techniques and lessons learned from a series of 83 patients. Neurosurgery 37:915921,1995

10. Cushing H: Tumors of the Nervus Acusticus and the Syndrome of the Cerebellopontile Angle. Philadelphia: WB Saunders, 1917

11. Dandy WE: An operation for the total removal of cerebellopontine (acoustic) tumors. Surg Gynecol Obstet 41:129-148, 1925

12. Darrouzet V, Martel J, Enée V, Bébéar JP, Guérin J: Vestibular schwannoma surgery outcomes: our multidisciplinary experience in 400 cases over 17 years. Laryngoscope 114:681-688, 2004

13. Darwish BS, Bird PA, Goodisson DW, Bonkowski JA, MacFarlane MR: Facial nerve function and hearing preservation after retrosigmoid excision of vestibular schwannoma: Christchurch Hospital experience with 97 patients. ANZ J Surg 75: 893-896, 2005

14. Delgado TE, Bucheit WA, Rosenholtz HR, Chrissian S: Intraoperative monitoring of facila muscle evoked responses obtained by intracranial stimulation of the facila nerve: a more accurate technique for facila nerve dissection. Neurosurgery 4:418-421, 1979

15. Eisenhardt L: Long postoperative survivals in cases of intracranial tumor. A Res Publ Ass Nerv Ment Dis Proc 16:390416, 1935

16. El-Kashlan HK, Zeitoun H, Arts HA, Hoff JT, Telian SA: Recurrence of acoustic neuroma after incomplete resection. Am J Otol 21:389-392, 2000

17. Friedman RA, Berliner KI, Bassim M, Ursick J, Slattery WH III, Schwartz MS, et al: A paradigm shift in salvage surgery for radiated vestibular schwannoma. Otol Neurotol 32:13221328,2011

18. Fuentes S, Arkha Y, Pech-Gourg G, Grisoli F, Dufour H, Régis J: Management of large vestibular schwannomas by combined surgical resection and gamma knife radiosurgery. Prog Neurol Surg 21:79-82, 2008

19. Fukuda M, Oishi M, Hiraishi T, Natsumeda M, Fujii Y: Clinicopathological factors related to regrowth of vestibular schwannoma after incomplete resection. Clinical article. J Neurosurg 114:1224-1231, 2011

20. Glasscock ME III, Kveton JF, Jackson CG, Levine SC, McKennan KX: A systematic approach to the surgical management of acoustic neuroma. Laryngoscope 96:1088-1094, 1986

21. Godefroy WP, van der Mey AG, de Bruine FT, Hoekstra ER, Malessy MJ: Surgery for large vestibular schwannoma: residual tumor and outcome. Otol Neurotol 30:629-634, 2009

22. Haque R, Wojtasiewicz TJ, Gigante PR, Attiah MA, Huang B, Isaacson SR, et al: Efficacy of facial nerve-sparing approach in patients with vestibular schwannomas. Clinical article. J Neurosurg 115:917-923, 2011

23. House JW, Brackmann DE: Facial nerve grading system. Otolaryngol Head Neck Surg 93:146-147, 1985

24. House WF: Partial tumor removal and recurrence in acoustic tumor surgery. Arch Otolaryngol 88:644-654, 1968

25. Iwai Y, Yamanaka K, Ishiguro T: Surgery combined with radiosurgery of large acoustic neuromas. Surg Neurol 59:283291,2003 
26. Jackler RK: Comparability in reporting outcomes: a scientific imperative. Am J Otol 17:811-812, 1996

27. Jung S, Kang SS, Kim TS, Kim HJ, Jeong SK, Kim SC, et al: Current surgical results of retrosigmoid approach in extralarge vestibular schwannomas. Surg Neurol 53:370-378, 2000

28. Kanzaki J, Tos M, Sanna M, Moffat DA, Monsell EM, Berliner KI: New and modified reporting systems from the consensus meeting on systems for reporting results in vestibular schwannoma. Otol Neurotol 24:642-649, 2003

29. Kartush JM, Brackmann DE: Acoustic neuroma update. Otolaryngol Clin North Am 29:377-392, 1996

30. Kirkpatrick PJ, Tierney P, Gleeson MJ, Strong AJ: Acoustic tumour volume and the prediction of facial nerve functional outcome from intraoperative monitoring. Br J Neurosurg 7:657-664, 1993

31. Lalwani AK, Butt FY, Jackler RK, Pitts LH, Yingling CD: Facial nerve outcome after acoustic neuroma surgery: a study from the era of cranial nerve monitoring. Otolaryngol Head Neck Surg 111:561-570, 1994

32. Lanman TH, Brackmann DE, Hitselberger WE, Subin B: Report of 190 consecutive cases of large acoustic tumors (vestibular schwannoma) removed via the translabyrinthine approach. J Neurosurg 90:617-623, 1999

33. Lee SH, Willcox TO, Buchheit WA: Current results of the surgical management of acoustic neuroma. Skull Base 12:189195, 2002

34. Mamikoglu B, Wiet RJ, Esquivel CR: Translabyrinthine approach for the management of large and giant vestibular schwannomas. Otol Neurotol 23:224-227, 2002

35. McClelland S III, Guo H, Okuyemi KS: Morbidity and mortality following acoustic neuroma excision in the United States: analysis of racial disparities during a decade in the radiosurgery era. Neuro Oncol 13:1252-1259, 2011

36. McElveen JT Jr, Belmonte RG, Fukushima T, Bullard DE: A review of facial nerve outcome in 100 consecutive cases of acoustic tumor surgery. Laryngoscope 110:1667-1672, 2000

37. Misra BK, Purandare HR, Ved RS, Bagdia AA, Mare PB: Current treatment strategy in the management of vestibular schwannoma. Neurol India 57:257-263, 2009

38. Nadol JB Jr, Chiong CM, Ojemann RG, McKenna MJ, Martuza RL, Montgomery WW, et al: Preservation of hearing and facial nerve function in resection of acoustic neuroma. Laryngoscope 102:1153-1158, 1992

39. Nam SI, Linthicum FH Jr, Merchant SN: Temporal bone histopathology in neurofibromatosis type 2. Laryngoscope 121:1548-1554, 2011

40. Patni AH, Kartush JM: Staged resection of large acoustic neuromas. Otolaryngol Head Neck Surg 132:11-19, 2005

41. Raftopoulos C, Abu Serieh B, Duprez T, Docquier MA, Guérit JM: Microsurgical results with large vestibular schwannomas with preservation of facial and cochlear nerve function as the primary aim. Acta Neurochir (Wien) 147:697-706, 2005

42. Raslan AM, Liu JK, McMenomey SO, Delashaw JB Jr: Staged resection of large vestibular schwannomas. Clinical article. J Neurosurg 116:1126-1133, 2012

43. Roland JT Jr, Fishman AJ, Golfinos JG, Cohen N, Alexiades G, Jackman AH: Cranial nerve preservation in surgery for large acoustic neuromas. Skull Base 14:85-91, 2004

44. Samii M, Gerganov VM, Samii A: Functional outcome after complete surgical removal of giant vestibular schwannomas. Clinical article. J Neurosurg 112:860-867, 2010
45. Sanna M, Russo A, Taibah A, Falcioni M, Agarwal M: Enlarged translabyrinthine approach for the management of large and giant acoustic neuromas: a report of 175 consecutive cases. Ann Otol Rhinol Laryngol 113:319-328, 2004

46. Silva J, Cerejo A, Duarte F, Silveira F, Vaz R: Surgical removal of giant acoustic neuromas. World Neurosurg 77:731-735, 2012

47. Sughrue ME, Kaur R, Rutkowski MJ, Kane AJ, Kaur G, Yang I, et al: Extent of resection and the long-term durability of vestibular schwannoma surgery. Clinical article. J Neurosurg 114:1218-1223, 2011

48. Torrens M, Maw R, Coakham H, Butler S, Morgan H: Facial and acoustic nerve preservation during excision of extracanalicular acoustic neuromas using the suboccipital approach. Br J Neurosurg 8:655-665, 1994

49. Tos M, Thomsen J: The translabyrinthine approach for the removal of large acoustic neuromas. Arch Otorhinolaryngol 246:292-296, 1989

50. Uziel A, Benezech J, Frerebeau P: Intraoperative facial nerve monitoring in posterior fossa acoustic neuroma surgery. Otolaryngol Head Neck Surg 108:126-134, 1993

51. van de Langenberg R, Hanssens PE, van Overbeeke JJ, Verheul JB, Nelemans PJ, de Bondt BJ, et al: Management of large vestibular schwannoma. Part I. Planned subtotal resection followed by Gamma Knife surgery: radiological and clinical aspects. Clinical article. J Neurosurg 115:875-884, 2011

52. Veronezi RJ, Fernandes YB, Borges G, Ramina R: Long-term facial nerve clinical evaluation following vestibular schwannoma surgery. Arq Neuropsiquiatr 66 (2A):194-198, 2008

53. Wiet RJ, Mamikoglu B, Odom L, Hoistad DL: Long-term results of the first 500 cases of acoustic neuroma surgery. Otolaryngol Head Neck Surg 124:645-651, 2001

54. Wu H, Sterkers J: Translabyrinthine removal of large acoustic neuromas in young adults. Auris Nasus Larynx 27:201-205, 2000

55. Yamakami I, Uchino Y, Kobayashi E, Yamaura A, Oka N: Removal of large acoustic neurinomas (vestibular schwannomas) by the retrosigmoid approach with no mortality and minimal morbidity. J Neurol Neurosurg Psychiatry 75:453-458, 2004

56. Zhang X, Fei Z, Chen YJ, Fu LA, Zhang JN, Liu WP, et al: Facial nerve function after excision of large acoustic neuromas via the suboccipital retrosigmoid approach. J Clin Neurosci 12:405-408, 2005

57. Zhao X, Wang Z, Ji Y, Wang C, Yu R, Ding X, et al: Long-term facial nerve function evaluation following surgery for large acoustic neuromas via retrosigmoid transmeatal approach. Acta Neurochir (Wien) 152:1647-1652, 2010

Manuscript submitted May 16, 2012.

Accepted July 20, 2012.

Current affiliation for Dr. Gurgel: Division of OtolaryngologyHead and Neck Surgery, University of Utah Hospitals and Clinics, Salt Lake City, Utah.

Please include this information when citing this paper: DOI: 10.3171/2012.7.FOCUS12199.

Address correspondence to: Ashkan Monfared, M.D., Division of Otolaryngology, George Washington University, $2021 \mathrm{~K}$ Street, NW, Suite 206, Washington, DC 20006. email: monfared@gmail. com. 